\title{
History of Analytic Philosophy
}

Series Editor: Michael Beaney, University of York, UK

Titles include:

Stewart Candlish

THE RUSSELL/BRADLEY DISPUTE AND ITS SIGNIFICANCE FOR TWENTIETHCENTURY PHILOSOPHY

Siobhan Chapman

SUSAN STEBBING AND THE LANGUAGE OF COMMON SENSE

Annalisa Coliva

MOORE AND WITTGENSTEIN

Scepticism, Certainty and Common Sense

Giuseppina D'Oro and Constantine Sandis (editors)

REASONS AND CAUSES

Causalism and Non-Causalism in the Philosophy of Action

George Duke

DUMMETT ON ABSTRACT OBJECTS

Mauro Engelmann

WITTGENSTEIN'S PHILOSOPHICAL DEVELOPMENT

Phenomenology, Grammar, Method, and the Anthropological View

Sébastien Gandon

RUSSELL'S UNKNOWN LOGICISM

A Study in the History and Philosophy of Mathematics

Jolen Galaugher

RUSSELL'S PHILOSOPHY OF LOGICAL ANALYSIS: 1897-1905

Nicholas Griffin and Bernard Linsky (editors)

THE PALGRAVE CENTENARY COMPANION TO PRINCIPIA MATHEMATICA

Anssi Korhonen

LOGIC AS UNIVERSAL SCIENCE

Russell's Early Logicism and Its Philosophical Context

Gregory Landini

FREGE'S NOTATIONS

What They Are and What They Mean

Sandra Lapointe

BOLZANO'S THEORETICAL PHILOSOPHY

An Introduction

Omar W. Nasim

BERTRAND RUSSELL AND THE EDWARDIAN PHILOSOPHERS

Constructing the World

Ulrich Pardey

FREGE ON ABSOLUTE AND RELATIVE TRUTH

An Introduction to the Practice of Interpreting Philosophical Texts 
Douglas Patterson

ALFRED TARSKI

Philosophy of Language and Logic

Erich Reck (editor)

THE HISTORIC TURN IN ANALYTIC PHILOSOPHY

Graham Stevens

THE THEORY OF DESCRIPTIONS

Russell and the Philosophy of Language

Mark Textor (editor)

JUDGEMENT AND TRUTH IN EARLY ANALYTIC PHILOSOPHY AND

PHENOMENOLOGY

Maria van der Schaar

G.F. STOUT AND THE PSYCHOLOGICAL ORIGINS OF ANALYTIC

PHILOSOPHY

Nuno Venturinha (editor)

WITTGENSTEIN AFTER HIS NACHLASS

Pierre Wagner (editor)

CARNAP'S LOGICAL SYNTAX OF LANGUAGE

Pierre Wagner (editor)

CARNAP'S IDEAL OF EXPLICATION AND NATURALISM

Forthcoming:

Andrew Arana and Carlos Alvarez (editors)

ANALYTIC PHILOSOPHY AND THE FOUNDATIONS OF MATHEMATICS

Rosalind Carey

RUSSELL ON MEANING

The Emergence of Scientific Philosophy from the 1920s to the 1940s

Sandra Lapointe (translator)

Franz Prihonsky

THE NEW ANTI-KANT

Consuelo Preti

THE METAPHYSICAL BASIS OF ETHICS

The Early Philosophical Development of G.E.Moore

History of Analytic Philosophy

Series Standing Order ISBN 978-0-230-55409-2 (hardcover)

Series Standing Order ISBN 978-0-230-55410-8 (paperback)

(outside North America only)

You can receive future titles in this series as they are published by placing a standing order. Please contact your bookseller or, in case of difficulty, write to us at the address below with your name and address, the title of the series and one of the ISBNs quoted above.

Customer Services Department, Macmillan Distribution Ltd, Houndmills, Basingstoke, Hampshire RG21 6XS, England 


\section{The Palgrave Centenary Companion to Principia Mathematica}

Edited by

Nicholas Griffin

McMaster University, Canada

and

Bernard Linsky

University of Alberta, Canada 
Selection and editorial matter (c) Nicholas Griffin and Bernard Linsky 2013

Chapters $\odot$ their individual authors 2013

Softcover reprint of the hardcover 1st edition 2013 978-1-137-34462-5

All rights reserved. No reproduction, copy or transmission of this publication may be made without written permission.

No portion of this publication may be reproduced, copied or transmitted save with written permission or in accordance with the provisions of the Copyright, Designs and Patents Act 1988, or under the terms of any licence permitting limited copying issued by the Copyright Licensing Agency, Saffron House, 6-10 Kirby Street, London EC1N 8TS.

Any person who does any unauthorized act in relation to this publication may be liable to criminal prosecution and civil claims for damages.

The authors have asserted their rights to be identified as the authors of this work in accordance with the Copyright, Designs and Patents Act 1988.

First published 2013 by

PALGRAVE MACMILLAN

Palgrave Macmillan in the UK is an imprint of Macmillan Publishers Limited, registered in England, company number 785998, of Houndmills, Basingstoke, Hampshire RG21 6XS.

Palgrave Macmillan in the US is a division of St Martin's Press LLC, 175 Fifth Avenue, New York, NY10010.

Palgrave Macmillan is the global academic imprint of the above companies and has companies and representatives throughout the world.

Palgrave ${ }^{\circledR}$ and Macmillan ${ }^{\circledR}$ are registered trademarks in the United States, the United Kingdom, Europe and other countries.

ISBN 978-1-349-46611-5

ISBN 978-1-137-34463-2 (eBook)

DOI $10.1057 / 9781137344632$

This book is printed on paper suitable for recycling and made from fully managed and sustained forest sources. Logging, pulping and manufacturing processes are expected to conform to the environmental regulations of the country of origin.

A catalogue record for this book is available from the British Library.

A catalog record for this book is available from the Library of Congress. 


\section{Contents}

Series Editor's Foreword vii

Acknowledgments $\quad$ x

Notes on Contributors $\quad \mathrm{xi}$

Note on Citations $\quad$ xiv

Introduction: Palgrave Centenary Companion to

$\begin{array}{ll}\text { Principia Mathematica } & \text { XV }\end{array}$

Part I The Influence of $P M$

1 Principia Mathematica: The First 100 Years 3 Alasdair Urquhart

2 David Hilbert and Principia Mathematica 21 Reinhard Kahle

3 Principia Mathematica in Poland 35 Jan Woleński

\section{Part II Russell's Philosophy of Logic and Logicism}

4 From Logicism to Metatheory

Patricia Blanchette

5 Russell on Real Variables and Vague Denotation Edwin Mares

6 The Logic of Classes of the No-Class Theory Byeong-uk $\mathrm{Yi}$

7 Why There Is No Frege-Russell Definition of Number Jolen Galaugher

\section{Part III Type Theory and Ontology}

8 Principia Mathematica: $\varphi$ ! versus $\varphi$ Gregory Landini

9 PM's Circumflex, Syntax and Philosophy of Types Kevin C. Klement 
vi Contents

10 Principia Mathematica, the Multiple-Relation

Theory of Judgment and Molecular Facts

James Levine

11 Report on Some Ramified-Type Assignment Systems and Their Model-Theoretic Semantics

Harold T. Hodes

12 Outline of a Theory of Quantification

Dustin Tucker

\section{Part IV Mathematics in $P M$}

13 Whatever Happened to Group Theory?

Nicholas Griffin

14 Proofs of the Cantor-Bernstein Theorem in

Principia Mathematica

391

Arie Hinkis

15 On Quantity and Number in Principia Mathematica:

A Plea for an Ontological Interpretation of the

Application Constraint

413

Sébastien Gandon

Bibliography

Index 


\section{Series Editor's Foreword}

During the first half of the twentieth century, analytic philosophy gradually established itself as the dominant tradition in the Englishspeaking world, and over the last few decades it has taken firm root in many other parts of the world. There has been increasing debate over just what 'analytic philosophy' means, as the movement has ramified into the complex tradition that we know today, but the influence of the concerns, ideas and methods of early analytic philosophy on contemporary thought is indisputable. All this has led to greater self-consciousness among analytic philosophers about the nature and origins of their tradition, and scholarly interest in its historical development and philosophical foundations has blossomed in recent years, with the result that history of analytic philosophy is now recognized as a major field of philosophy in its own right.

The main aim of the series in which the present book appears, the first series of its kind, is to create a venue for work on the history of analytic philosophy, consolidating the area as a major field of philosophy and promoting further research and debate. The 'history of analytic philosophy' is understood broadly, as covering the period from the last three decades of the nineteenth century to the start of the twenty-first century, beginning with the work of Frege, Russell, Moore and Wittgenstein, who are generally regarded as its main founders, and the influences upon them, and going right up to the most recent developments. In allowing the 'history' to extend to the present, the aim is to encourage engagement with contemporary debates in philosophy, for example, in showing how the concerns of early analytic philosophy relate to current concerns. In focusing on analytic philosophy, the aim is not to exclude comparisons with other - earlier or contemporary - traditions, or consideration of figures or themes that some might regard as marginal to the analytic tradition but which also throw light on analytic philosophy. Indeed, a further aim of the series is to deepen our understanding of the broader context in which analytic philosophy developed, by looking, for example, at the roots of analytic philosophy in neo-Kantianism or British idealism, or the connections between analytic philosophy and phenomenology, or discussing the work of philosophers who were important in the development of analytic philosophy but who are now often forgotten. 
The present volume, edited by Nicholas Griffin and Bernard Linsky, two of the leading scholars of Russell's philosophy, celebrates the centenary of Principia Mathematica, published in three volumes by Bertrand Russell (1872-1970) and Alfred North Whitehead (1861-1947) in 1910, 1912 and 1913. It was in this work that Russell and Whitehead sought to demonstrate logicism - the thesis that mathematics can be reduced to logic. Gottlob Frege (1848-1925) had attempted to demonstrate logicism about arithmetic (though not geometry) in the period from 1879, when his first book, Begriffsschrift, was published, to 1903, when the second volume of his Grundgesetze der Arithmetik appeared. However, in 1902, as that second volume was in press, Russell had written to him informing him of the contradiction that he had discovered in Frege's system. Frege had attempted to respond to the contradiction - now known as Russell's paradox - in a hastily written appendix, but he soon realized that his response was inadequate and abandoned his logicist project. It was left to Russell to find a solution to the paradox and to reconstruct the logicist program accordingly. The final result was Russell's ramified theory of types and Principia Mathematica itself, but this theory and the logicist reconstruction in which it was embedded took a decade to develop.

Russell's first attempt to demonstrate logicism was in The Principles of Mathematics, published in 1903, but it was only when he had introduced the theory of descriptions in 1905 that he felt able to deal properly with the paradox. He also joined forces with Whitehead, his former mathematics tutor, who had himself published an important book in 1898, $A$ Treatise on Universal Algebra. Both had plans to publish second volumes, but they decided to come together in doing so, the result being not just one further volume but the three volumes of Principia Mathematica.

As Griffin and Linsky note in their introduction to the present book, however, while Principia Mathematica is widely acknowledged as one of the classic texts of analytic philosophy, it has probably been read in its entirety by very few. The philosophical ideas that Russell developed in leading up to Principia Mathematica have been the subject of a great deal of scholarly work over recent years, coinciding with the emergence of history of analytic philosophy as a recognized field of philosophy. But there has been rather less attention paid to the details of Principia Mathematica itself. The present book, as the first collection of essays devoted to the work, takes a major step in filling this gap. With chapters from both established scholars and the new generation of historians of analytic philosophy, it explores both the logical and philosophical ideas of Principia Mathematica and their historical development and influence, focusing on Russell's contribution. 
It is fitting that this collection should appear in the centenary year of the publication of the third volume of Principia Mathematica, to inaugurate a new stage in our understanding of one of the great works of the twentieth century.

Michael Beaney

May 2013 


\section{Acknowledgments}

The editors cannot sufficiently express their gratitude to Kenneth Blackwell and Arlene Duncan for their help in preparing this volume. In the present dismal state of word processing software, any attempt to convert technical material prepared via different programs in different formats into a single format becomes a major research undertaking. This was undertaken with extraordinary persistence and resourcefulness by Ken Blackwell, without whose help it would have been literally impossible to assemble the volume. In addition, he constantly reminded us of inconsistencies of formatting, of which, without him, we would have been oblivious. Implementing the conversion, in some cases symbol by symbol, was the work of Arlene Duncan, whose patience and diligence in handling unfamiliar symbols and multiple fonts in recalcitrant software are truly remarkable. We would also like to thank Shen Storm for his meticulous work in checking quotations. 


\section{Notes on Contributors}

Patricia Blanchette is Professor of Philosophy at the University of Notre Dame in Indiana. She has written a number of articles on the history and philosophy of logic and is the author of Frege's Conception of Logic.

Jolen Galaugher is currently a postdoctoral fellow at the University of Iowa. She is working on the history of early analytic philosophy and early modern philosophy. Her book Russell's Philosophy of Logical Analysis (1897-1905) is forthcoming.

Sébastien Gandon is Professor of Philosophy at the Université Blaise Pascal in Clermont, France. He is the author of Russell's Unknown Logicism, and of several papers on early analytic philosophy, history of mathematics and philosophy of mathematics.

Nicholas Griffin is Director of the Bertrand Russell Centre at McMaster University, Hamilton, Ontario, where he holds a Canada Research Chair in Philosophy. He has written widely on Russell, is the author of Russell's Idealist Apprenticeship and the general editor of The Collected Papers of Bertrand Russell.

Arie Hinkis lives in Israel, and is the author of Proofs of the CantorBernstein Theorem. A Mathematical Excursion. He has been a student, a soldier, a project manager, an entrepreneur, a poet and a financial engineer. He now plans to become a wandering lecturer on the history of Cantorian set theory and the theory of proof-processing by gestalt and metaphoric descriptors.

Harold T. Hodes is Associate Professor of Philosophy at Cornell University. He specializes in logic, the foundations of mathematics, the philosophy of logic and the philosophy of mathematics.

Reinhard Kahle is Professor at CENTRIA and the Department of Mathematics, FCT, Universidade Nova de Lisboa, Portugal. His research is on mathematical proof theory via history of logic and philosophy of mathematics to philosophical logic. He has edited a volume Intensionality, and with Volker Peckhaus has written on 'Hilbert's Paradox'.

Kevin C. Klement is Associate Professor of Philosophy at the University of Massachusetts, Amherst. He is the author of Frege and the Logic of 
Sense and Reference and has published on Bertrand Russell's philosophical logic, the history of analytical philosophy, and formal and informal logic.

Gregory Landini is Professor of Philosophy at the University of Iowa. His books on Russell and related issues are: Russell's Hidden Substitutional Theory; Wittgenstein's Apprenticeship with Russell; Russell; and Frege's Notations: What They Are and How They Mean. He has written on topics in the history and philosophy of logic and mathematics, the philosophy of mind, and Wittgenstein's Tractatus.

James Levine is Associate Professor of Philosophy at Trinity College, Dublin. He works primarily in the area of early analytic philosophy. Recent publications include 'Logic and Solipsism', 'From Moore to Peano to Watson: The Mathematical Roots of Russell's Naturalism and Behaviorism', and 'Analysis and Abstraction Principles in Russell and Frege'.

Bernard Linsky is Professor of Philosophy at the University of Alberta in Edmonton. His books are: Russell's Metaphysical Logic; On Denoting 1905-2005, edited with Guido Imaguire; and The Evolution of Principia Mathematica: Bertrand Russell's Manuscripts and Notes for the Second Edition. He has also written on other topics in the history of logic, early analytic philosophy, the philosophy of language and metaphysics.

Edwin Mares is Professor of Philosophy at Victoria University of Wellington and a founder and member of Victoria's Centre for Logic, Language and Computation. He has written on non-classical logic (especially relevant logic), history of philosophy, epistemology and metaphysics. His books are Relevant Logic: A Philosophical Interpretation and Realism and Antirealism (with Stuart Brock).

Dustin Tucker is Assistant Professor of Philosophy at Colorado State University in Fort Collins, Colorado. He has published on intensional paradoxes in the context of Frank Ramsey's work.

Alasdair Urquhart is Professor Emeritus of Philosophy and Computer Science at the University of Toronto, and President of the Association for Symbolic Logic (2013-16). He is the editor of Volume 4 of The Collected Papers of Bertrand Russell, and has published widely in logic and related areas.

Byeong-uk Yi is Associate Professor of Philosophy at the University of Toronto. He has written Understanding the Many, and many articles 
on logic, philosophy of language, metaphysics, philosophy of science, ancient philosophy, and semantics of classifier languages.

Jan Woleński is Professor of Philosophy, Jagiellonian University, Krakow, Poland, is a member of the Polish Academy of Sciences, the Polish Academy of Sciences and Arts, and the International Institute of Philosophy. He is the author of Logic and Philosophy in the Lvov-Warsaw School, Essays in the History of Logic and Logical Philosophy, Essays on Logic and Its Applications to Philosophy, and Historico-Philosophical Essays. 


\section{Note on Citations}

There are two editions of Principia Mathematica:

Whitehead and Russell, Principia Mathematica, Cambridge: Cambridge

University Press, 3 volumes: 1910, 1912, 1913.

Whitehead and Russell, Principia Mathematica, Cambridge: Cambridge

University Press, 3 volumes: 1925, 1927.

The substantive changes in the second edition consist of the addition of a long new introduction, three appendices, and a very useful list of defined symbols, all of which are to be found in the first volume. The new introduction and the three appendices were written by Russell alone. The first two volumes were reset for the second edition, allowing some minor corrections to be made, but beyond the new introduction and the three appendices the two editions are substantially the same. However, the pagination of the first two volumes differs somewhat between the two editions. Much later, a paperback abridgement was published:

Whitehead and Russell, Principia Mathematica to *56 Cambridge: Cambridge University Press, 1962.

It included the material added in the second edition, with the exception of Appendix B, in which the proof of mathematical induction was known to be defective. The list of definitions was abridged to *56.

In the present work, all page references, except where otherwise indicated, are to the second edition, which is by the far the most widely available. Whenever it is necessary to compare the two editions, the first is cited as $P M_{1}$ and the second as $P M_{2}$. On the very rare occasions that it is necessary to refer to the abridgement, it is cited as $P M a$.

All works by Whitehead and Russell are cited by acronyms, a list of which appears at the beginning of the Bibliography, which appears at the end of the volume. All works by other authors are cited by author and date. 


\section{Introduction}

\section{Palgrave Centenary Companion to Principia Mathematica}

Nicholas Griffin and Bernard Linsky

By any standards, the nineteenth century saw astonishing developments in mathematics. From non-Euclidean geometry at the century's beginning to the development of set theory and group theory at its end, mathematics in the nineteenth century underwent not one but several major transformations. As the century drew to a close three major movements rose to prominence. One was a drive towards generality and abstraction, that by mid-century had seen metric geometry expand from the study of Euclidean space to the study of generalized Riemannian manifolds, that saw the development of new number systems and that saw, by the end of the century, the emergence of set theory through the work of Georg Cantor. Set theory offered for the first time the prospect of dealing with the problems of infinity and, in the twentieth century, would come to be seen as providing a comprehensive basis for mathematics. The second was a drive towards increased rigor which produced the first precise definition of a limit in the calculus and, by the end of the century, was producing an explosion of axiomatizations of mathematical theories which were, for the first time, truly rigorous and fully explicit. The most ambitious and self-conscious of these late-nineteenth-century attempts at rigour was that of the Italian mathematician, Guiseppe Peano, who, in a collaborative effort with a number of followers, was attempting to provide rigorous and explicit proofs of all established mathematical results, using a symbolic notation of his own devising. The third theme was an increased philosophical interest in the nature of mathematical concepts themselves. Various efforts along these lines appeared throughout the century, but the one of greatest relevance here is the work of the German mathematician, Gottlob Frege, who, having developed modern quantified logic, went on to provide a definition of the concept of number and to argue that 
the whole of arithmetic could be derived from logic. These three themes came together on a truly epic scale in the three volumes of Principia Mathematica, which Alfred North Whitehead and Bertrand Russell published between 1910 and 1913.

Principia Mathematica had its origins in Russell's discovery of the work of Peano at the International Congress of Philosophy held in Paris in the summer of 1900, which Peano and his supporters attended in force. To that time Russell had been working for several years attempting to develop a satisfactory philosophy of mathematics. Despite some philosophical successes, notably in rejecting the Hegelian and Kantian approaches he had originally tried, a satisfactory outcome had always eluded him. At the conference, however, he very quickly realized that the Peano school had a set of techniques of which he could make use, and on his return from the conference he immediately set about applying them. As a result, he quickly rewrote The Principles of Mathematics, which he had started in 1899, finishing the new version by the end of the year. It was published, after some delay and substantial revisions of Part I, in 1903, billed as the first of two volumes. It was intended as a philosophical introduction to, and defence of, the logicist program that all mathematical concepts could be defined in terms of logic and that all mathematical theorems could be derived from purely logical axioms. It was to be followed by a second volume, done in Peano's notation, in which the logicist program would actually be carried out by providing the requisite definitions and proofs. At about the time Russell was finishing The Principles of Mathematics, he began the collaboration with his former teacher, Whitehead, that produced, many years later, Principia Mathematica.

Whitehead in 1898 had published A Treatise on Universal Algebra, another first volume, in which a variety of symbolic systems were interpreted on a general, abstract conception of space. Again much detailed formal work was held over for the second volume. By September 1902 the two second volumes had merged, both authors having decided to unite in producing a joint second volume to each of their projects. This in turn grew until it constituted the three volumes of Principia Mathematica. The long delay in completing PM was not due to any expansion in the program of work intended - indeed, the scope of the three volumes of $P M$ as actually published was considerably narrower than what had been promised in the Principles. The chief reason for the delay was the difficulty in dealing with a paradox that Russell had discovered around May 1901 in the set-theoretic basis of the logicist system. The natural initial supposition of that system was that a class 
would correspond to each propositional function of the system, intuitively the class of terms which satisfied that propositional function. This being the case, there would be a class corresponding to the propositional function ' $\hat{x}$ is not a member of itself', and this class would be a member of itself if and only if it was not a member of itself. The problem of restricting the underlying logic so that this result could not arise while leaving it strong enough to support the mathematical superstructure Russell and Whitehead wished to build on it absorbed many years of intense labour.

With the exception of Gandon's contribution, there is little mention of Whitehead's part in the collaboration in this volume. From correspondence between Whitehead and Russell, and from Russell's later published statements, it is clear that the collaboration was close and involved every portion of the text going between the two authors for revisions. Russell was responsible for the Introduction, Whitehead devised much of the notation, and was intending, even as late as 1923, to be primarily responsible for the fourth volume on Geometry, which never appeared. (See Linsky, 2011: 15-19, for this information about the 1920s, and a discussion of the evidence about the writing of the second edition.) The authors in this volume focus on the philosophical and mathematical portions of Principia Mathematica, which were primarily the work of Russell, and the historical papers make use of materials from the Bertrand Russell Archives, but it is hoped that, with work being done now on the Whitehead-Russell correspondence, more will come to light about Whitehead's side of the collaboration.

The first volume of Principia Mathematica was published by Cambridge University Press in 1910 in an edition of 750 copies. The second and third volumes appeared in 1912 and 1913, respectively, but with a print run of only 500 copies. This edition was all that was available until a second edition, with three new appendices and a long new introduction, all written by Russell alone, was published in 1925-27. Since then the three volumes have rarely if ever been out of print, and since 1962 a single-volume paperback edition, Principia Mathematica to *56, of the first 385 pages and Appendices A and $\mathrm{C}$ of the second edition, has been available. Until the 1930s $P M$ dominated thinking about logic and the foundations of mathematics. Philosophers struggled painfully to come to terms with it. Mathematicians pondered what it had to teach them about the most fundamental concepts of mathematics - or else grumbled about what they saw as the needless complexities in which it had entangled their subject. Many of the generation of logicians who came to maturity between the two world wars learnt their logic direct from 
PM: until the 1930s there were few other options. Thinkers in various fields - from textual scholarship to biology - attempted to apply its ideas in new areas. But, by the time the second edition appeared, the subject of mathematical logic was already being developed in new directions, primarily by Hilbert's students in Göttingen and by Twardowski's students in Poland, and, with the work of Gödel and Tarski in the early 1930 's, was about to take the form it has had to this day with the development of model-theoretic semantics and Gödel's incompleteness theorems. These results took mathematical logic beyond $P M$, the first because there could be no extensional model theory based on classes in $P M$, and the second because it seemed to put an end to the hope of deriving mathematics from logic alone.

In the 1930s, also, new, more user-friendly introductions to mathematical logic began to proliferate so that it was no longer necessary to use $P M$ as a textbook. $P M$ came to seem so vast, so difficult, and, ultimately, so unfamiliar that only specialists ventured beyond a few comfortingly familiar sections early in the first volume. And so $P M$ achieved its current status as an acknowledged classic that is, however, seldom read and is hardly known at all to the public outside of symbolic logic. None the less, it does have a minor celebrity in popular culture as an icon of intellectual difficulty, while among logicians it is universally recognized by its initials alone. And in 1999, it appeared as number 23 in the Modern Library's list of the twentieth century's hundred greatest non-fiction works, provoking incredulity from John Cassidy in The New Yorker (31 May, 1999) about 'a must-read book that is, for all intents and purposes, unreadable'. In fact, as the papers in this collection show, it is not unreadable; though it is undeniably difficult. And its current status as a great but little-studied masterpiece means both that much of genuine value in it has been overlooked and that its role in the development of mathematical logic has not been properly appreciated. Yet $P M$ was, for the first 25 years of the twentieth century, the most influential work on logic and was, moreover, a model for the new approach to philosophy, which came to be identified as Analytic Philosophy.

$P M$ has entered the domain of historical investigation, and scholars have begun to examine what archival materials relate directly to its creation. There is not a great deal of material: a few draft manuscripts of sections that went back and forth between Whitehead and Russell and some surviving letters (mainly from Whitehead), currently being edited. Even the final manuscript, some 4,500 pages long, that Russell reports delivering to the publisher in an 'old four-wheeler' specially hired for the occasion (Auto. 1: 152), has disappeared. The only sur- 
viving fragments are a single page enclosed with a letter to Ottoline Morrell, now in the Humanities Research Center at the University of Texas at Austin, and another page and a half in the Bertrand Russell Archives, where Russell's remaining correspondence and all of the other Russell manuscripts cited in this volume are kept. Whitehead's papers relating to $P M$, including what must have been a sizeable chunk of manuscript for the missing fourth volume on geometry, were presumably destroyed, along with his other papers, by his widow on his instructions. More archival material exists for the creation of the second edition, and this has been extensively studied in Linsky (2011). The work in this volume is based in part on unpublished manuscripts and published works other than $P M$, but some comes solely from the published text of $P M$ and the subsequent development of logic. The collection demonstrates, however, that there is an ongoing study of issues raised in $P M$, and, more directly related to our goal here, that results are emerging about the actual philosophy and logic of $P M$ that have been overshadowed by subsequent developments in the field.

The first three papers, by Alasdair Urquhart, Reinhard Kahle and Jan Woleński, present the story of the influence of $P M$. Urquhart carries the history of the influence and 'reception' of $P M$ on through the middle of the twentieth century. He charts the process by which $P M$ ceased to be cutting-edge logic and became the little-read classic described above. He explains that, as logic became a technical subject, the content of $P M$ was simplified, theorems proved in more natural ways, and so, as is only natural, the work fell out of the active citations in the field (as represented by a study of the Journal of Symbolic Logic) and, like most great works in the history of mathematics more than one hundred years old, became for logicians a work of primarily historical interest.

When it first appeared, $P M$ was influential even among those who developed logic in different directions from those taken by Russell and Whitehead. Kahle's contribution describes the influence of $P M$ on David Hilbert and his 'Göttingen School', where it acquired the reputation that it now has among mathematical logicians. Kahle relies on lecture notes and correspondence to conclude that Hilbert's interest in $P M$ was always as a model of an axiomatic, formalized system of logic, in keeping with his ongoing interest in axiomatic systems of mathematics. Although Hilbert's foundational project developed away from the logicism of PM, he continued to regard it as a model axiomatic foundation for mathematics. Kahle's paper reveals the extent to which current attitudes to $P M$ originated with Hilbert. For example, Hilbert's 
lectures are the source of the now widespread view that objections to the logicism of $P M$ centered on the axiom of reducibility.

Woleński shows the role that $P M$ played in the thinking of the Polish school of logic. Russell in old age joked that he knew of only six people who had read the later parts of $P M$ : 'Three of these were Poles, subsequently (I believe) liquidated by Hitler. The other three were Texans, subsequently successfully assimilated' (MPD: 86). Woleński writes of the history of the reception of $P M$ in Poland, showing the extensive attention to $P M$ which was the background to the extensional treatment of logic that was then current, and to Tarski's later development of model theory. He provides some plausible guesses as to the identities of the Poles and suggests additional names of Polish logicians who may well have read all three volumes.

The four papers in the next group variously illustrate ways in which the ideas actually in PM have been misconceived or overlooked by commentators who too closely assimilated them to post-PM thinking about logic. Patricia Blanchette enters into the discussion of Russell's so-called 'universal conception of logic' (from van Heijenoort, 1967b) in accordance with which model theory, the notion of completeness, and even talk of the independence of axioms of logic, is alien to the conception of logic embodied in PM. She traces Russell's views to the time of the Principles, and to a view of models that was natural for Russell given his mathematical training in geometry. The models constructed in the discovery of Non-Euclidean Geometry are possible spaces where, for example, lines are interpreted as circles on the surface of a sphere. It is then possible to find a model where the notions of line, point, direction, etc. are interpreted by geometrical entities with unusual properties, thus showing, for example, that the 'parallel postulate' of Euclidean geometry could be shown false while the other postulates were true. Blanchette shows that this notion of model, while natural to considering axioms of geometry, is not easily adapted to showing independence or other model-theoretic features of logic.

Edwin Mares addresses the distinction in PM between free variables, which Whitehead and Russell call 'real', and bound variables, which are termed 'apparent' variables. In The Principles of Mathematics, Russell thinks of real variables as ambiguously or arbitrarily denoting their values. This seems like a primitive attempt to grasp the notion of a variable assignment and one which we might expect to have been abandoned once Russell adopted the new theory of denoting in 1905. But Mares argues that the doctrine of arbitrary denotation was retained for far longer and in fact appears as the doctrine of vague denotation in 'On 
Propositions' (1919) and The Analysis of Mind (1921) and even plays a (metatheoretical) role in the second edition of $P M$, despite the ban on real variables within the logic of the second edition. Again, we have a case in which close attention to Russell's text reveals a rather surprising historical record, much different from the modern orthodoxy towards which he is often thought to be confusedly groping.

The project of $P M$ was to develop a sizeable portion of elementary mathematics, based on a theory of classes which was safe from the paradoxes. As an alternative to axiomatic set theory - which treats sets as real and avoids paradox by adding axioms that are descriptive of an intuitive notion of set, but limited in power so as to avoid paradox the approach of $P M$ is to define classes using the background theory of propositional functions, allowing the theory of types to preclude paradoxes. Whitehead and Russell use the notation ' $\hat{x} F x^{\prime}$ as an abstract referring to the class of $F$ s, as we would now write ' $\{x$ : $F x\}$ '. Providing a 'contextual definition', allowing the elimination of class expressions from a context $C \ldots$, a formula $C(\hat{x} F x)$ becomes a formula in which no class expression occurs, hence the term 'no-classes' theory. The replacement is a quantified expression saying that some (predicative) function equivalent to $F$, in fact, does have the property $C$. (The notion of predicative function will recur in the discussions in this book, but is not germane to this particular issue.) Of course this 'no-classes theory' is modeled on Russell's famous theory of definite descriptions, going back to 'On Denoting' in 1905, and which Russell himself said provided the clue to the ultimate solution of the paradoxes in PM.

Byeong-uk Yi gives a critical examination of this theory of classes in PM. He argues that the theory has logical problems: 'The class of $F s$ is elegant' and 'The class of $F s$ is interesting', on the theory, do not imply 'The class of $F$ s is elegant and interesting' (and the same problem arises for $P M$ 's analysis of numbers, e.g., the number of $F s$, as classes of classes). This objection recalls the difficulties of so-called 'opaque' intensional contexts involving knowledge and belief for class expressions first raised by Boër (1973). By considering treatments of plural constructions (e.g., 'the $F s^{\prime}$ ) that relate to Russell's earlier notion of class as many in POM, Yi formulates a way of amending PM's theory to avoid the logical problems and argues that the amended theory leads to a sophisticated intensionalist view of class, one that identifies classes with functions of a special kind. Yi rejects this view on the grounds that it cannot yield proper accounts of some plural constructions (e.g., 'Those who wrote $P M$ are two'), and concludes that the logical notion of class is incoherent. 
While the definition of natural numbers as classes of equinumerous classes is familiarly known as the 'Frege-Russell' definition of numbers and is often presented as the first, and most important, step in the reduction of mathematics to logic which characterizes 'logicism' as a philosophical project, Jolen Galaugher in fact focuses on the difference between the account of numbers in Frege and in PM. Frege's account is familiar from Grundlagen der Arithmetik (1884) and, in final form in the Grundgesetze der Arithmetik (1893, 1903a), which Russell studied in preparation for Appendix A to Principles of Mathematics, 'The Logical and Arithmetical Doctrines of Frege'. Frege's theory makes use of classes as objects, the extensions, or courses of values of a concept, and so his theory is deeply involved in both his fundamental distinction between concepts and objects, and the theory of courses of values which gave rise to the paradoxes. Russell arrived at the view that numbers are classes of classes from a very different route, influenced by his discovery of the paradoxes, and having a different view of what he called 'definitions by abstraction', as they appeared through 'Hume's Principle' in Frege. Russell saw the relation between a propositional function, the 'class as many' and the 'class as one' in a very different way from Frege's distinction between a concept and its course of values. Galaugher relies on previously untranslated correspondence with Couturat to show the difference in approach to logic and the resulting logicism of Frege and then Whitehead and Russell.

The next series of papers enters into the interpretation of the fundamental notion of Principia Mathematica, the logic of propositional functions and the theory of types governing that logic. Russell's views on philosophical logic had gone through several radical changes during the period in which Whitehead and Russell were working out the technical symbolic logic of the body of PM. The Introduction to PM was written by Russell, even incorporating a paper, 'The Theory of Logical Types', presented under his own name in 1910, though appearing in PM with revisions by Whitehead. In his 1908 paper, 'Mathematical Logic as Based on the Theory of Types', Russell presents what seems to be a different conception of philosophical logic as underlying the theory of types to that presented in PM, without any indication of the changes in the eventual introduction. The changes in view between Principles and $P M$ center on changes in the account of propositions and their constituents through the period. The results of Russell's abandonment of denoting concepts as constituents of propositions and their replacement with individuals in 'On Denoting' are clearly evident in all the approaches tried after 1905. But in between 'On Denoting' and PM, there was the so 
called 'substitutional' theory, studied by Gregory Landini in his groundbreaking Russell's Hidden Substitutional Theory (1998a), by which the underlying logic consists of propositions and individuals which may be 'substituted' one for the other, thus avoiding the whole need for propositional functions at all. When one adds to this the obvious skepticism about propositions themselves in the Introduction to $P M$, it is unclear what to make of the apparent assertions about propositions and propositional functions in that work. Gregory Landini's contribution provides an overview of, and argument for, his radical reinterpretation of the philosophical logic underpinning $P M$, offering his 'nominalist semantics' for the higher-order quantifier as a replacement for an apparent commitment to propositional functions in that work. Landini's interpretation has been at the center of philosophical discussion of $P M$ in recent years.

Kevin Klement's essay picks up part of this discussion, centering on one reason often given for considering $P M$ to be a logic of propositional functions, namely that there are seeming terms for propositional functions. These are represented with another use of the circumflex, different from that in class terms, namely ' $F \hat{x}$ ', used to symbolize examples such as 'Socrates is human' as resulting from the application to Socrates of the function ' $\hat{x}$ is human'. At issue here is the difference between the occurrence of an expression as a predicate, as in '... is human', and as a term, or name, as 'Socrates'. The circumflex notation makes it seem possible to make functions themselves subjects of further predications, as in Russell's example 'Humanity characterizes Socrates', which would seem to have the form $G(\hat{x}$ is human). In keeping with the nominalist interpretation pioneered by Landini, Klement nonetheless differs from Landini by arguing that such propositional-function abstracts are used in $P M$ only either schematically or as arguments to propositionalfunction variables of higher type within quantified statements the truth-values of which depend upon statements in which the propositional function abstract is absent. Klement contrasts this view of property abstraction with Frege's approach which preceded it and to Church's which followed.

While Klement and Landini differ on exactly how to understand propositional function abstracts in $P M$, they share a nominalist approach to the interpretation of $P M$. Such approaches, however, remain controversial, and James Levine takes issue with them. One respect in which there is agreement concerns the status of propositions in $P M$, namely that propositions do not have the ontological standing in $P M$ that they enjoyed in the Principles. This is the result of their elimination 
as 'incomplete symbols' by means of Russell's 'multiple relation theory of judgment'. Despite this agreement, however, nominalists and realists disagree about what the multiple-relation theory entails. In his paper, Levine argues that it does not entail that propositions in PM are sentences, nor that Russell rejected molecular facts as truth-makers of molecular propositions, nor that Russell in PM rejected logical objects as constituents of truth-makers. In the course of his discussion, Levine shows that, as Alonzo Church (1984a, fn 4) suspected, the sections of the Introduction that banish propositions (PM I: 44, 45) were in fact late additions to the work. Further, Levine argues that Russell's assumption that molecular facts are among the truth-makers created a problem he came to recognize when he attempted to develop the multiple relation theory of judgment in his 1913 manuscript Theory of Knowledge, a problem that, aside from any criticisms Wittgenstein made, contributed to his decision to abandon that work. Levine concludes by arguing that since Russell indicates in 1911 that 'individuals' are 'beings in the actual world', while holding also at that time that universals, including logical constants are not, the doctrine of the unrestricted ('individual') variable, which is a centerpiece of Landini's interpretation, is not part of $P M$.

Mathematical logicians, since Quine, have begun their discussions of the theory of types by expressing dismay at the confusion about the very notion of 'propositional functions' in Principia. (See Chihara (1973), for example.) Underlying this puzzlement is the fact that the propositional functions of $P M$ are very different from the functions of contemporary mathematical logic. A mathematical function is commonly treated nowadays as a set among others, (for monadic functions) a set of ordered pairs with the second element of each pair the value of the function for the first as argument. $P M$ itself treats such mathematical functions, such as $\sin x$, the successor function $x^{\prime}$, and so on, as 'descriptive functions', using the theory of definite descriptions to allow their definition in the logic of relations. Thus, for example, 'the successor of $x^{\prime}$ is analyzed, using the relation $S x y$, ' $x$ is a successor of $y^{\prime}$, as 'the $x$ such that $S x y^{\prime}$, or in their notation, ' $S$ ' $y$ '. This method allows the reduction of the logic of mathematical functions to that of propositional functions. Those looking for an interpretation of propositional functions as a species of the more familiar mathematical functions will be frustrated by $P M$.

Harold Hodes reveals the unusual nature of propositional functions when expressed in the logic of the $\lambda$-calculus. In mathematics, one frequently wants to understand a term containing a free variable, for 
example ' $x^{2}+3$ ', as representing the value of a mathematical function for an argument represented by that variable. The $\lambda$-calculus permits the construction, from such a term, of a new 'abstraction term' to represent this function, in this case, ' $\left(\lambda x \cdot x^{2}+3\right)$ '. The application of this function to the number 2 is represented as ' $\left(\lambda x \cdot x^{2}+3\right)(2)$ '. The ' $\beta$-conversion' rule yields a term for the value of this function: $2^{2}+3$. If one views propositional functions $\hat{x} F x$, as functions from individuals to propositions, then one will represent this as $(\lambda x . F x)(a)$, which ' $\beta$-converts' to the proposition $\mathrm{Fa}$ as its value. Hodes' interest is in applying the $\lambda$-calculus to represent a theory of propositional functions when the underlying logic is typed, in fact, when it has the features of the 'ramified theory of types'. In the ramified theory of types not only functions and their arguments are of different types, but even propositions, which are the values of those functions, are themselves distinguished into different types (called 'orders'). Hodes is able to make clear sense of several puzzles about $P M$, including the absence of explicit indices indicating the types of arguments in favour of what Whitehead and Russell call 'typical ambiguity' of expressions. There is a tradition, which Hodes traces to Haskell Curry, of treating types as assigned to terms on the basis of a given assignment of types to free variables in those terms. Thus an expression is a term only relative to such an assignment, called a 'typecontext', and what are usually called 'formation rules' are rules that define a three-place relation holding between type-contexts, terms and the types of those terms. A formula will be a term of propositional type. In this way, formulas as written are not seen as missing type indices, which must yet be supplied, but rather as missing a value for a contextual feature that is required to semantically interpret that formula. The three kinds of type-assignment systems presented in this paper all differ in certain respects from what $P M$ might offer, but for one of them Hodes defines a model-theoretic semantics which should shed some light on how to understand languages whose logic is that outlined in $P M$.

Dustin Tucker also tackles the difficulties of ramification. After Ramsey in the 1920s drew the distinction between the semantic paradoxes and the set-theoretic paradoxes, Russell's ramified type theory came to be disdained: the set-theoretic paradoxes could be solved by the simple theory of types, and the semantic paradoxes were to be solved by other means. Yet, as Tucker notes, not all paradoxes succumbed to Ramsey's neat dichotomy. Ramification was harder to avoid than Ramsey thought. And yet for all its complexity it is, as Tucker points out, a very blunt instrument. No hint of paradox attaches to 'All 
sentences in this introduction are in English', yet ramified type theory bans it since it falls within the range of its own quantifier. Taking his initial inspiration from Kripke's famous treatment of the semantic paradoxes (Kripke, 1975), Tucker proposes a new theory of quantification, a theory of 'compressed ramification', which bans circular quantification by forcing the proposition in which the quantifier occurs up to a higher level than the propositions it quantifies over, only when there is danger of paradox.

The final three papers, those of Nicholas Griffin, Arie Hinkis and Sébastien Gandon, delve into the mathematical content of $P M$, going beyond the philosophical theory of types and propositional functions presented in the Introduction. Nicholas Griffin approaches the problem of showing exactly what portions of the mathematics of Russell's day are covered in PM and which are missing. While it is well-known that Whitehead was to be sole author of a Volume IV of $P M$ on geometry, which never appeared, there are other gaps in the mathematical content of $P M$, which seems to be limited to the theory of numbers, set theory, the beginnings of the theory of infinite cardinals and ordinals, and the theory of measurement and real numbers. A striking absence is the theory of groups, being developed in the years in which $P M$ was composed, and having the abstract, axiomatic formulation that would seem to suit it well for inclusion in $P M$. Griffin's essay explains the history of Russell's interest in group theory and explains why the theory is not more prominently represented in $P M$.

Arie Hinkis shows that there is a substantial mathematical content to the 'Cantor-Bernstein Theorem' of which no less than four versions are proved in PM. This theorem, called the 'Schröder-Bernstein theorem' in $P M$ (and elsewhere), asserts that if an infinite set $A$ can be mapped one to one into an infinite set $B$, and vice versa, then $A$ and $B$ are equinumerous. Hinkis finds that each of the four proofs of the Cantor-Bernstein theorem in PM reveals, or showcases, some aspect of the formal system of $P M$. Hinkis joins the general consensus that the no-classes theory of $P M$ is not an elegant or efficient way to prove theorems about set theory, but he does reveal that the mathematical content of $P M$, the proofs of theorems in the later sections, are genuine, sound proofs. Hinkis also considers the consequences for the first proof of dropping the axiom of reducibility in the second edition of $P M$.

Sébastien Gandon discusses the theory of measurement and real numbers which occurs in Part VI, which is the last part of Volume III of $P M$. The set theoretic approach to real numbers constructs them as 
Dedekind cuts, or sets, of rational numbers, which in turn are set-theoretic constructions (pairs) of natural numbers. Whitehead and Russell (and there is some discussion of the comparative roles of the two in constructing this theory in Gandon's essay) instead construct real numbers using families or relations between relations. Two relations $R$ and $S$ may be said to be in the ratio $n / m$ if $n$ iterations of $R$ is equivalent to $m$ iterations of $S$, or $R^{n}=S^{m}$. This is an extension of the Archimedean theory of proportion in Euclid. Such relations, which help to construct rational numbers, are then related to each other in further structures to construct real numbers. As Gandon shows, in addition to being the natural way to construct the real numbers in a logic in which relations and not sets are basic, the theory also makes the real numbers directly applicable in the measurement of quantities. The title for section VI is indeed 'Quantity'. Gandon compares other theories of real numbers, including that of Frege in Grundgesetze, with the PM theory in the respect of how they can be applied in measurement. Where Frege had urged the applicability of counting to his own account of natural numbers (if there are four moons of Jupiter then the set of those very moons will be a member of the set which constructs the number 4), the theory of real numbers is not so directly applied. Like other set-theoretic constructions, what Frege constructs is an object which is in a way isomorphic to quantities, in the fashion studied in modern measurement theory. The $P M$ approach directly shows what features a quantity must have to be represented by real numbers.

With his essay Gandon has led us into the very details of the later volumes that Russell thought had been insufficiently studied. We join the three Poles and three Texans of the anecdote in knowing what goes on in those later sections. Even if these later sections were not as directly influential as Urquhart suggests the earlier logical material was in the development of symbolic logic in the twentieth century, we still end up with a much better understanding of the accomplishment of Whitehead and Russell just over one hundred years ago. 